\title{
New alternatives for estimating the octanol/water partition coefficient and water solubility for volatile organic compounds using GLC data (Kovàts retention indices)
}

\author{
Felicia Spafiu, ${ }^{\mathrm{a}}$ Alice Mischie, ${ }^{\mathrm{a}}$ Petre Ionita, ${ }^{\mathrm{a}}$ Adrian Beteringhe, ${ }^{\mathrm{a}}$ Titus Constantinescu, \\ and Alexandru T. Balaban ${ }^{b}, *$ \\ "Institute of Physical Chemistry "Ilie Murgulescu” of the Romanian Academy, Splaiul \\ Independentei 202, 060021 Bucharest, Romania \\ ${ }^{b}$ Texas A\&M University at Galveston, 5007 Avenue U, Galveston, TX 77551, USA \\ E-mail: balabana@,tamug.edu, titelconstantinescu@yahoo.com
}

\begin{abstract}
New possibilities for estimating octanol/water partition coefficients $(\log P)$ and the water solubility $\left(S_{w}\right)$ were investigated using Kovàts retention indices $(I)$ obtained from GLC retention data for 132 volatile organic compounds belonging to 7 different chemical classes (hydrocarbons, alcohols, aldehydes, ketones, carboxylic acids, esters and halogen compounds). Application of the multilinear regression method led to six equations, all involving index $I$, as follows: ( $i)$ direct correlation $\log P$ vs. $I$ (eq.1); (ii) $\log P$ vs. $I$, molar refractivity, and surface tension (eq. 2); (iii) $\log P$ vs. $I$ and structural characteristics (eqs. 3, 4 and 6); (iv) $\log P$ vs. the $I / S_{w}$ ratio (eq. 5). Excepting eq. 1 (which showed relatively weak correlations), eqs. $2-6$ can provide reliable values for $\log P$ and for $\log S_{w}$ as proved by the significant statistical parameters. The general models presented through eqs. $2-6$ may also be applied in estimation of other biological and/or ecological important properties, which are linearly dependent on the $\log P$ or $\log S_{w}$ values. By generalization, a new calculation method is suggested (eq. 7), in order to allow the estimation of $\log P$ or $\log S_{w}$ in terms of the number of bonds and the Kovàts retention index.
\end{abstract}

Keywords: $\log P$, water solubility, Kovàts index, physical properties, QSPR

\section{Introduction}

The estimation of hydrophobic/hydrophilic properties of chemical compounds is relevant for many fields including medicine, pharmacology, foods, fragrances, chemical industry and environmental protection. These properties are measured by the octanol/water partition coefficient $(\log P)$ and the water solubility under normal conditions $\left(S_{w}\right)^{1-10}$ both having current 
applications in estimating various characteristics of interest for biology and environmental studies. $^{11-13}$

In order to obtain experimental $\log P$ values, liquid/liquid ( $1 / 1)$ extraction (octanol/water or, generally, organic solvent/water) may be applied. As an alternative to this time-consuming method, the Hansch model provides the $\log P$ values from the experimental fragment and bond increments. ${ }^{1,2}$ Besides this, several theoretical models for predicting $\log P$ and $\log S_{w}$ values were proposed . ${ }^{3-10,14-16}$ Another improvement of the classical $1 / 1$ extraction is offered by reversedphase liquid chromatography (RP-HPLC) ${ }^{17,18}$ and reversed-phase thin-layer chromatography (RP-TLC), ${ }^{19-21}$ which are at present the most frequently used techniques for providing experimental values of the octanol/water partition coefficients. Such methods are based on the linear correlation between $\log P$ values of the corresponding compounds and the capacity factors (for RP-HPLC) or $\mathrm{RM}_{0}$ values (in the case of RP-TLC), when reliable correlations are obtained within homologous series. In the case of volatile compounds, gas liquid chromatography (GLC) may provide more suitable alternatives.

The retention index on a certain stationary phase $^{22}$ is the result of a gas-liquid partition process, so that it may contain information related to solvation. Such information can be extracted from GLC data, under the form of well-known solubility factors, ${ }^{23-25}$ which are used for the calculation of various properties, including $\log P$. Besides this indirect method, only few attempts of evaluating directly physico-chemical properties from GLC data have been reported, ${ }^{26}$ such studies being restricted to polycyclic aromatic derivatives.

The aim of the present study is to investigate the possibility of estimating the hydrophobic/hydrophilic properties of organic compounds, namely $\log P$ and $\log S_{w}$, from Kovàts indices $(I)$ for a set of 132 organic compounds from 7 different classes. In order to obtain relationships suitable for structurally diverse sets, the simple correlations $\log P$ vs. $I$ were improved by addition of other parameters, such as molar refractivity, surface tension, number of bonds, accessible polar surface, or water solubility.

\section{Results and Discussion}

The use of the index $I$ for estimation of the $\log P$ value and water solubility was carried out in the present study as a stepwise strategy, which allowed drawing up of some new linear relationships between the mentioned parameters and the index $I$. The predictability of $\log P$ and $\log S_{w}$ through the performed models was tested by cross-validation, using the leave-one-out method. ${ }^{27}$ The leave-one-out cross-validation coefficient $\left(R^{2} \mathrm{CV}\right)$ was provided by the CODESSA program. ${ }^{28}$ Additionally, the quality factor of the regressions $(Q)$ was calculated as $R / S E .^{29,30}$

The set of compounds and the corresponding literature-accessible values for $\log P, 1,31,32$ $S_{w}{ }^{6,7,32}$ and $I$ index ${ }^{24}$ are presented in Table 1 (stationary phase polyphenyl ether). 
Table 1. Experimental values for Kovàts index $(I), \log P$ and water solubility $\left(S_{w}\right)$ for the studied set of compounds

\begin{tabular}{|c|c|c|c|c|}
\hline & Compound & $\log P \exp$ & $I$ & $S_{w}(\mathrm{~mol} / \mathrm{l})$ \\
\hline \multicolumn{5}{|c|}{ Hydrocarbons } \\
\hline 1 & ethane & 1.81 & 200 & $2.007 \times 10^{-3}$ \\
\hline 2 & propane & 2.36 & 300 & $1.418 \times 10^{-3}$ \\
\hline 3 & n-butane & 2.89 & 400 & $1.055 \times 10^{-3}$ \\
\hline 4 & n-pentane & 3.39 & 500 & $5.27 \times 10^{-4}$ \\
\hline 5 & n-hexane & 4 & 600 & $1.1 \times 10^{-4}$ \\
\hline 6 & n-heptane & 4.5 & 700 & $3.39 \times 10^{-5}$ \\
\hline 7 & n-octane & 5.15 & 800 & $5.78 \times 10^{-6}$ \\
\hline 8 & n-nonane & 5.65 & 900 & $1.72 \times 10^{-6}$ \\
\hline 9 & n-decane & 6.25 & 1000 & $3.65 \mathrm{E} \times 10^{-7}$ \\
\hline 10 & n-undecane & 6.54 & 1100 & $2.81 \times 10^{-8}$ \\
\hline 11 & n-dodecane & 6.8 & 1200 & - \\
\hline 12 & n-tridecane & 7.5 & 1300 & - \\
\hline 13 & n-tetradecane & 8 & 1400 & - \\
\hline 14 & 2-methylpropane & 2.76 & 358 & $8.4 \times 10^{-4}$ \\
\hline 15 & 3-methylheptane & - & 774 & $6.92 \times 10^{-6}$ \\
\hline 16 & 2,4-dimethylpentane & - & 608 & $5.49 \times 10^{-5}$ \\
\hline 17 & ethane & 1.13 & 270 & $4.67 \times 10^{-3}$ \\
\hline 18 & propene & 1.77 & 360 & $4.753 \times 10^{-3}$ \\
\hline 19 & 1-butene & 2.4 & 450 & $3.939 \times 10^{-3}$ \\
\hline 20 & 1-pentene & 2.8 & 552 & $2.11 \times 10^{-3}$ \\
\hline 21 & 1-hexene & 3.4 & 614 & $5.94 \times 10^{-4}$ \\
\hline 22 & 1-heptene & 3.99 & 723 & $1.85 \times 10^{-4}$ \\
\hline 23 & 1-octene & 4.57 & 819 & $3.65 \times 10^{-5}$ \\
\hline 24 & E-2-octene & 4.44 & 849 & - \\
\hline 25 & 2-ethylhexene & 4.31 & 824 & - \\
\hline 26 & 2-butyne & 1.46 & 587 & - \\
\hline 27 & 1-octyne & 3.57 & 907 & - \\
\hline 28 & 2-octyne & 3.57 & 979 & - \\
\hline 29 & benzene & 2.15 & 833 & $2.482 \times 10^{-2}$ \\
\hline 30 & toluene & 2.73 & 938 & $5.709 \times 10^{-3}$ \\
\hline 31 & ethylbenzene & 3.15 & 1035 & $1.592 \times 10^{-3}$ \\
\hline
\end{tabular}




\begin{tabular}{|c|c|c|c|c|}
\hline 32 & styrene & 2.95 & 1094 & $2.976 \times 10^{-3}$ \\
\hline 33 & ethynylbenzene & 2.4 & 1096 & $4.464 \times 10^{-3}$ \\
\hline 34 & $o$-xylene & 3.12 & 1046 & $1.677 \times 10^{-3}$ \\
\hline 35 & $m$-xylene & 3.2 & 1050 & $1.51 \times 10^{-3}$ \\
\hline 36 & $p$-xylene & 3.15 & 1041 & $1.52 \times 10^{-3}$ \\
\hline 37 & mesitylene & 3.42 & 1155 & $4.01 \times 10^{-4}$ \\
\hline 38 & $\alpha$-pinene & 4.83 & 1015 & $1.83 \times 10^{-5}$ \\
\hline 39 & cyclohexane & 3.44 & 735 & - \\
\hline \multicolumn{5}{|c|}{ Alcohols } \\
\hline 40 & methanol & -0.77 & 522 & 31.21 \\
\hline 41 & ethanol & -0.31 & 587 & 21.7 \\
\hline 42 & 1-propanol & 0.25 & 703 & 16.63 \\
\hline 43 & 1-butanol & 0.88 & 820 & $8.52 \times 10^{-1}$ \\
\hline 44 & 1-pentanol & 1.56 & 929 & $2.49 \times 10^{-1}$ \\
\hline 45 & 1-hexanol & 2.03 & 1032 & $5.7 \times 10^{-2}$ \\
\hline 46 & 1-heptanol & 2.72 & 1138 & $1.43 \times 10^{-2}$ \\
\hline 47 & 1-octanol & 3.07 & 1241 & $4.14 \times 10^{-3}$ \\
\hline 48 & 1-nonanol & 4.02 & 1350 & $9.7 \times 10^{-4}$ \\
\hline 49 & 1-decanol & 4.57 & 1439 & $2.34 \times 10^{-4}$ \\
\hline 50 & 1-undecanol & 4.72 & 1569 & $1.11 \times 10^{-4}$ \\
\hline 51 & 1-dodecanol & 5.13 & 1678 & $2.15 \times 10^{-5}$ \\
\hline 52 & 2-methyl-1-butanol & 1.16 & 886 & $3.36 \times 10^{-1}$ \\
\hline 53 & 3-methyl-1-butanol & 1.42 & 885 & $3.02 \times 10^{-1}$ \\
\hline 54 & allyl alcohol & 0.17 & 715 & 17 \\
\hline 55 & 2-hexen-1-ol & 1.6 & 1046 & - \\
\hline 56 & 2-butanol & 0.61 & 737 & 2.44 \\
\hline 57 & 2-hexanol & 1.76 & 950 & $1.34 \times 10^{-1}$ \\
\hline 58 & 2-propanol & 0.05 & 613 & 16.63 \\
\hline 59 & 3-hexanol & 1.65 & 941 & - \\
\hline 60 & 2-methyl-2-propanol & 0.35 & 654 & 13.49 \\
\hline 61 & 2-methyl-2-butanol & 0.89 & 771 & 1.13 \\
\hline 62 & 2-methyl-2-pentanol & 1.39 & 868 & - \\
\hline 63 & 3-methyl-3-pentanol & 1.41 & 900 & - \\
\hline 64 & 3-methyl-3-heptanol & - & 1078 & $1.83 \times 10^{-2}$ \\
\hline 65 & $\alpha$-terpineol & 2.98 & 1426 & $4.603 \times 10^{-3}$ \\
\hline 66 & dimethylcyclohexanol & 2.37 & 1173 & - \\
\hline
\end{tabular}




\begin{tabular}{|c|c|c|c|c|}
\hline 67 & cyclopentanol & 0.78 & 996 & 1.5 \\
\hline \multicolumn{5}{|c|}{ Aldehydes } \\
\hline 68 & acetaldehyde & -0.22 & 541 & 22.7 \\
\hline 69 & propionaldehyde & 0.3 & 656 & 5.26 \\
\hline 70 & butyraldehyde & 0.83 & 753 & $9.84 \times 10^{-1}$ \\
\hline 71 & hexanal & 1.89 & 966 & $5.63 \times 10^{-2}$ \\
\hline 72 & heptanal & 2.42 & 1066 & $1.09 \times 10^{-2}$ \\
\hline 73 & octanal & 2.9 & 1167 & $4.36 \times 10^{-3}$ \\
\hline 74 & 2-methyl-1-propanal & 0.77 & 706 & - \\
\hline 75 & propenal & -0.01 & 659 & 3.78 \\
\hline 76 & $E$-2-butenal & 0.52 & 870 & 2.58 \\
\hline 77 & $E$-2-hexenal & 1.58 & 1077 & - \\
\hline 78 & benzaldehyde & 1.48 & 1272 & $6.54 \times 10^{-2}$ \\
\hline \multicolumn{5}{|l|}{ Ketones } \\
\hline 79 & acetone & -0.24 & 652 & 17 \\
\hline 80 & 2-butanone & 0.29 & 764 & 3.092 \\
\hline 81 & 2-pentanone & 0.91 & 857 & $4.99 \times 10^{-1}$ \\
\hline 82 & 2-hexanone & 1.38 & 966 & $1.74 \times 10^{-1}$ \\
\hline 83 & 2-heptanone & 1.98 & 1061 & $3.76 \times 10^{-2}$ \\
\hline 84 & 2-octanone & 2.37 & 1165 & $7.01 \times 10^{-3}$ \\
\hline 85 & 2-nonanone & 3.14 & 1264 & $2.60 \times 10^{-3}$ \\
\hline 86 & 2-decanone & 3.73 & 1366 & $4.91 \times 10^{-4}$ \\
\hline 87 & 2-undecanone & 4.09 & 1469 & $1.16 \times 10^{-4}$ \\
\hline 88 & 2-dodecanone & 4.55 & 1571 & - \\
\hline 89 & 3-hexanone & 1.45 & 945 & $1.46 \times 10^{-1}$ \\
\hline 90 & cyclopentanone & 0.38 & 1050 & - \\
\hline 91 & cyclohexanone & 0.81 & 1160 & $2.54 \times 10^{-1}$ \\
\hline 92 & cycloundecanone & 3.66 & 1757 & - \\
\hline 93 & cyclododecanone & 4.1 & 1875 & - \\
\hline 94 & acetophenone & 1.58 & 1387 & $5.10 \times 10^{-2}$ \\
\hline 95 & Carvone & 2.52 & 1566 & $8.72 \times 10^{-3}$ \\
\hline \multicolumn{5}{|c|}{ Carboxylic acids } \\
\hline 96 & acetic acid & -0.17 & 734 & 16.65 \\
\hline 97 & propionic acid & 0.33 & 886 & 13.49 \\
\hline 98 & butyric acid & 0.79 & 985 & $6.80 \times 10^{-1}$ \\
\hline 99 & valeric acid & 1.39 & 1108 & $2.34 \times 10^{-1}$ \\
\hline
\end{tabular}


100 hexanoic acid

101 heptanoic acid

102 octanoic acid

103 nonanoic acid

104 decanoic acid

105 undecanoic acid

106 dodecanoic acid

107 2-methylpropionic acid

108 2-methylbutyric acid

109 3-methylbutyric acid

110 4-methylpentanoic acid
1.92

2.42

3.05

3.42

4.09

4.42

4.6

0.94

1.18

1.16

1.79

Esters

111 methyl acetate

0.18

1233

$8.83 \times 10^{-2}$

112 ethyl acetate

0.73

113 2-methylbutyl acetate

2.29

114 propyl acetate

1.24

115 butyl acetate

1.82

116 3-methylbutyl acetate

2.25

117 propyl butyrate

2.15

118 methyl propionate

0.82

119 propyl formate

0.83

120 isobutyl isobutyrate

2.48

121 isopentyl isovalerate

3.62

122 benzyl acetate

1.96

1358

$2.16 \times 10^{-2}$

1483

$5.47 \times 10^{-3}$

608

$1.79 \times 10^{-3}$

1733

$3.59 \times 10^{-4}$

1858

$2.80 \times 10^{-4}$

1982

$2.4 \times 10^{-5}$

945

1.89

1094

$4.39 \times 10^{-1}$

1042

$3.97 \times 10^{-1}$

1148

$-$ 


\section{Estimation of $\log P$ using the Kovàts retention index (I)}

\subsection{Simple correlation of the $\log P$ parameter with the Kovàts index(I)}

As it may be observed from Figure $1, \log P$ is linearly dependent on index $I$ within various homologous series. Plotting $\log P$ vs. $I$ also shows trends, depending on the functional group, unsaturation, and the presence of rings or aromatic structures.

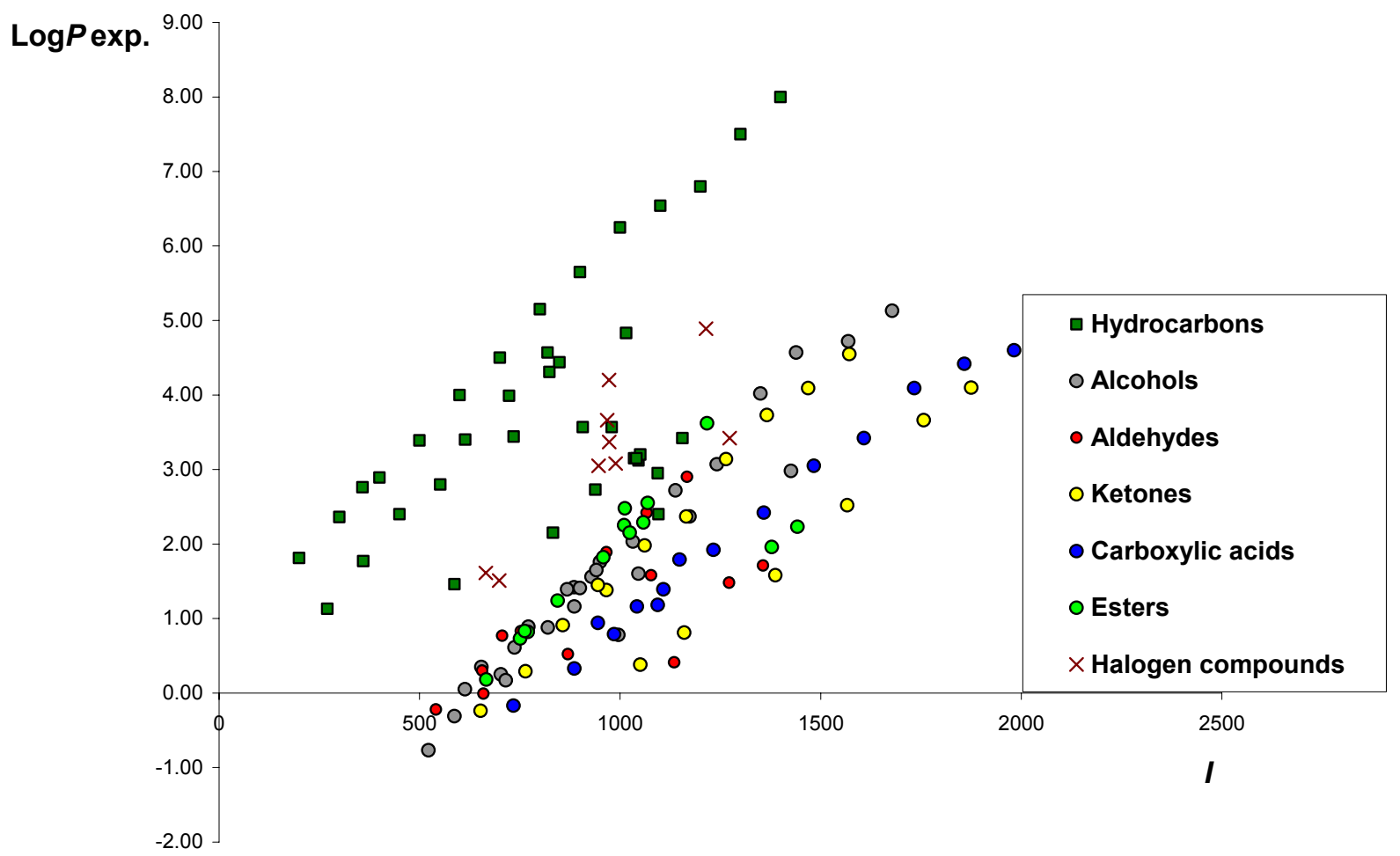

Figure 1. Plot of $\log P$ parameter (experimental, Table 1) vs. I.

In order to obtain linear relationships between $\log P$ and $I$, sets were formed according to functional groups, as shown in Table 1. Because the experimental $I$ values presented in Table 1 are about two orders greater than $\log P$, index $I$ was replaced in the calculations with the ratio $I / 100$, denoted as $I^{*}$. Linear regressions were performed according to a general equation (eq. 1), leading to relatively weak correlations $\left(R^{2}=0.431-0.990\right)$. Statistics of these correlations are presented in Table 2.

$$
\log P=a \times I^{*}+b
$$

eq. 1

where: $I^{*}=I($ Kovàts index, Table 1$) / 100$ 
Table 2. The coefficients $a, b$ and statistical parameters ${ }^{\mathrm{a}}\left(R, F, S E, R_{C V}^{2}, Q\right)$ in the case of eq. 1 , for each class of compounds (according to Table 1)

\begin{tabular}{cccccccccc}
\hline Eq. & Class $^{\mathrm{b}}$ & $\mathrm{N}$ & $a$ & $b$ & $R^{2}$ & $F$ & $S E$ & $R_{C V}^{2}$ & $Q$ \\
\hline 1a & Hydrocarbons & 37 & 0.352 & 0.938 & 0.431 & 26.52 & 1.265 & 0.361 & 0.518 \\
1b & Alcohols & 27 & 0.493 & -3.135 & 0.948 & 457.5 & 0.360 & 0.938 & 2.702 \\
1c & Aldehydes & 11 & 0.462 & -1.913 & 0.703 & 21.35 & 0.569 & 0.508 & 1.472 \\
1d & Ketones & 17 & 0.369 & -2.383 & 0.728 & 40.28 & 0.810 & 0.672 & 1.053 \\
1e & Carboxylic & 15 & 0.400 & -3.034 & 0.990 & 1299 & 0.156 & 0.985 & 6.371 \\
& acids & & & & & & & & \\
1f & Esters & 13 & 0.292 & -1.158 & 0.568 & 14.46 & 0.641 & 0.358 & 1.174 \\
1g & Halogen & 9 & 0.446 & -1.120 & 0.666 & 13.98 & 0.675 & 0.382 & 1.208 \\
& comp. & & & & & & & & \\
\hline
\end{tabular}

(') $R=$ Pearson's correlation coefficient; $F=$ Fisher test; $S E=$ standard error; $R_{C V}^{2}=$ cross validated coefficient; $Q=$ quality factor.

There are significant differences between the correlation parameters corresponding to the various classes, but such differences may be due rather to the heterogeneous composition of the sets, with respect to the olefinic, cyclic or aromatic structures. The best correlation coefficients were observed in the case of alcohols $\left(R^{2}=0.948\right)$ and carboxylic acids $\left(R^{2}=0.990\right)$. Such pronounced linearity may be explained by the smaller proportion of unsaturated, cyclic or aromatic structures within these sets.

\subsection{Dependence of the $\log P$ parameter on the Kovàts index(I) and physical properties (molar refractivity and surface tension)}

Eq. 1 was improved, according to the general equation 2, by the addition of a second parameter, constructed from two physical properties (molar refractivity and surface tension) which affect the partition process between water and the organic solvent. The molar refractivity and surface tension were computed using the ACD ChemSketch 8.0 Freeware software. ${ }^{33}$ Coefficients and statistical parameters of eqs. $2 \mathrm{a}-2 \mathrm{~g}$, corresponding to each class of compounds, are presented in Table 3. These results show significant increases of the correlation coefficients $\left(R^{2}=0.927-\right.$ 0.992). At the same time, a good correlation between $\log P$ values calculated through eqs. $2 \mathrm{a}-2 \mathrm{~g}$ and the experimental $\log P$ is displayed by Figure 2 .

$$
\log P=a \times I^{*}+b \times \log (\mathrm{MR} / \mathrm{ST})+c
$$

eq. 2

where: $\mathrm{MR}=$ molar refractivity and $\mathrm{ST}=$ surface tension. 
Table 3. Coefficients $a, b, c$ and statistical parameters $\left(R^{2}, F, S E, R_{C V}^{2}, Q\right)^{\mathrm{a}}$ in the case of eq. 2, for each class of compounds (according to Table 1)

\begin{tabular}{ccccccccccc}
\hline Eq. & Class & $\mathrm{N}$ & $a$ & $b$ & $c$ & $R^{2}$ & $F$ & $S E$ & $R_{C V}^{2}$ & $Q$ \\
\hline 2a & Hydrocarbons & 37 & 0.134 & 11.54 & 0.969 & 0.927 & 216.7 & 0.459 & 0.912 & 2.097 \\
2b & Alcohols & 27 & 0.402 & 2.218 & -2.315 & 0.959 & 283.2 & 0.325 & 0.944 & 3.013 \\
2c & Aldehydes & 11 & 0.156 & 6.214 & -0.183 & 0.938 & 61.48 & 0.274 & 0.890 & 3.534 \\
2d & Ketones & 17 & 0.160 & 7.145 & -0.673 & 0.958 & 161.9 & 0.328 & 0.928 & 2.984 \\
2e & Carboxylic acids & 15 & 0.330 & 1.523 & -2.113 & 0.992 & 839.4 & 0.137 & 0.986 & 7.270 \\
2f & Esters & 13 & 0.143 & 6.581 & -0.153 & 0.970 & 165.5 & 0.175 & 0.922 & 5.627 \\
2g & Halogen comp. & 9 & 0.179 & 6.402 & 0.996 & 0.980 & 149.3 & 0.177 & 0.921 & 5.592 \\
\hline
\end{tabular}

(') $R=$ Pearson's correlation coefficient; $F=$ Fisher test; $S E=$ standard error; $R_{C V}^{2}=$ cross validation coefficient; $Q=$ quality factor.

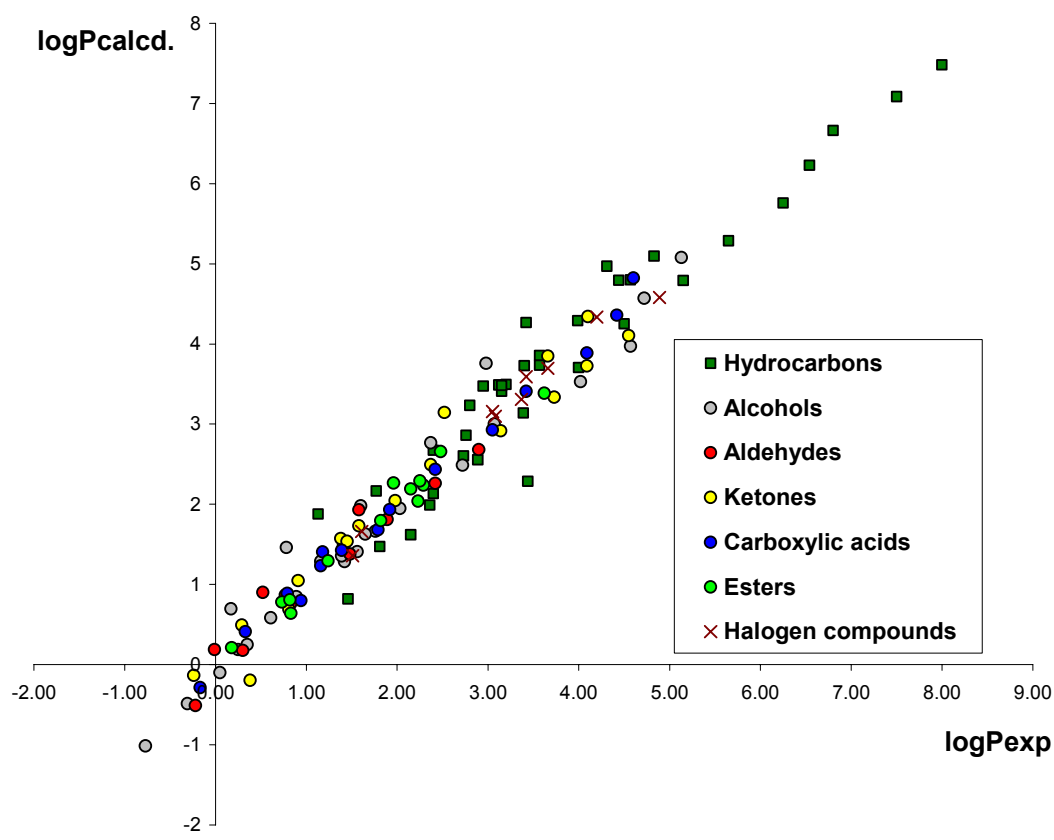

Figure 2. Plot of $\log P$ calcd. (eq.2, Table 3) vs. $\log P$ exp. (Table 1).

\subsection{Dependence of the $\log P$ parameter on the Kovàts index involving structural effects and accessible polar surface}

Another improvement of eq. 1 was achieved by a QSPR study. According to the observed influence of the molecular structure on the dependence $\log P$ vs. I (Figure 1), two parameters were added to eq.1: the number of bonds $(\mathrm{nBt})^{34}$ in order to characterize the effects of unsaturation, rings, or aromaticity, and the accessible polar surface, which may describe the availability of the functional group to hydration. Ascribing net atomic charges (CNDO) and 
geometry optimization $\left(\mathrm{MM}^{+}\right.$force field) were performed using the HyperChem program, ${ }^{35}$ followed by computing of the accesssible surface of the heteroatoms.

As seen in Table 4 and Figure 3, the use of the number of bonds nBt (a constitutional descriptor) together with index $I$ (eq. 3) led to a significant increase of statistical parameters, compared to eq. 1 .

$$
\log P=a \times I^{*}+b \times \mathrm{nBt}+c
$$

eq. 3

where $\mathrm{nBt}=$ number of bonds.

Table 4. The coefficients $a, b$ and statistical parameters ${ }^{\mathrm{a}}\left(R, F, S E, R_{C V}^{2}, Q\right)$ in the case of eq. 3 , for each class of compounds (according to Table 1)

\begin{tabular}{ccccccccccc}
\hline Eq. & Class & $\mathrm{N}$ & $a$ & $b$ & $c$ & $R^{2}$ & $F$ & $S E$ & $R_{C V}^{2}$ & $Q$ \\
\hline 3a & Hydrocarbons & 37 & -0.118 & 0.213 & 0.517 & 0.990 & 1842 & 0.162 & 0.979 & 6.141 \\
3b & Alcohols & 27 & 0.183 & 0.119 & -2.414 & 0.970 & 399.7 & 0.275 & 0.961 & 3.583 \\
3c & Aldehydes & 11 & 0.057 & 0.152 & -1.418 & 0.988 & 334.4 & 0.120 & 0.976 & 8.284 \\
3d & ketones & 17 & -0.031 & 0.187 & -1.686 & 0.984 & 443.5 & 0.200 & 0.970 & 4.959 \\
3e & Carboxylic & 15 & 0.201 & 0.082 & -2.170 & 0.993 & 889.5 & 0.133 & 0.988 & 7.493 \\
& acids & & & & & & & & & \\
3f & Esters & 13 & 0.079 & 0.134 & -1.586 & 0.975 & 200.1 & 0.160 & 0.915 & 6.171 \\
3g & Halogen & 9 & 0.152 & 0.118 & -0.084 & 0.982 & 171.3 & 0.165 & 0.923 & 6.005 \\
& comp. & & & & & & & & & \\
\hline
\end{tabular}

(') $R=$ Pearson's correlation coefficient; $F=$ Fisher test; $S E=$ standard error; $R_{C V}^{2}=$ cross validation coefficient; $Q=$ quality factor.

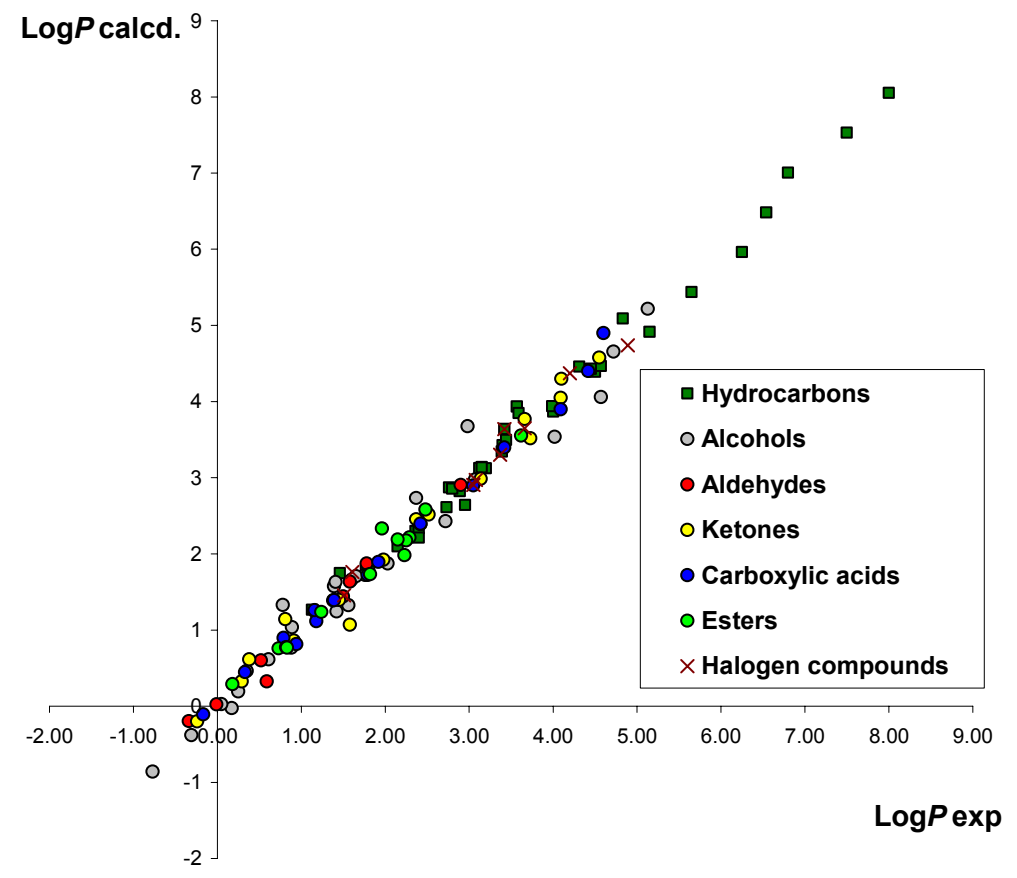

Figure 3. Plot of $\log P$ calc (eq. 3, Table 4) vs . $\log P$ exp. (Table 1). 
Attempts were made for finding a unique relationship able to predict $\log P$ of all the 129 compounds (for which experimental $\log P$ was available, Table 1), independent of the type of the functional group. In this case, supplementary characteristics of the functional group are required for these compounds. The accessible polar surface was found to be the best from several tested descriptors. It was included in the QSPR model (eq. 4) as a substituent factor (SF), only in the case of heteroatom-containing structures. Satisfactory statistics could be achieved only by adding an indicator variable $(V)$ to the QSPR model, so that $V$ has value "1" for those structures which contain oxygen atoms, and " 0 " for the other ones.

$$
\begin{gathered}
\log P=0.031 \times I^{*}+0.185 \times \mathrm{nBt}+6.05 \times 10^{-3} \times \mathrm{SF}+0.353 \times V \\
N=129 ; R^{2}=0.974 ; F=1194.4, S E=0.275, R_{C V}^{2}=0.969, Q=3.840
\end{gathered}
$$

where: $I^{*}=I($ Kovats index, Table 1$) / 100, \mathrm{nBt}=$ number of bonds, $\mathrm{SF}=\mathrm{Sp}=$ solvent accessible surface of the heteroatoms; for hydrocarbons, $\mathrm{SF}=0 ; V=1$ for compounds containing oxygen atoms, and $V=0$ for the other ones.

In Figure 4 the $\log P$ calcd. values (calculated via eq. 4 ) are plotted against the experimental values $\log P$ exp.

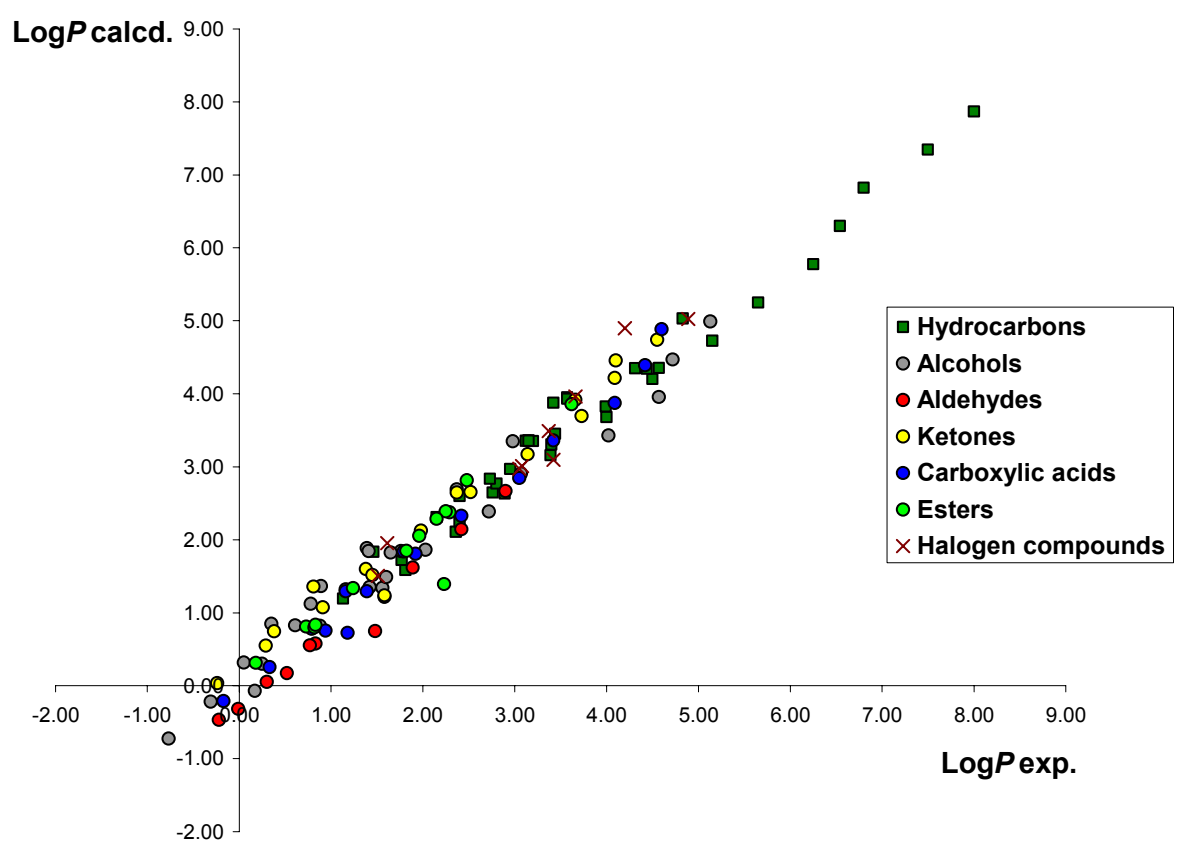

Figure 4. Plot of $\log P$ calcd. (eq.4) vs. $\log P \exp$ (Table 1)

Although $R$ is slightly lower than in the case of eqs. $3 \mathrm{a}-3 \mathrm{~g}$, the statistical parameters of eq. 4 $\left(R^{2}=0.974, F=1194.4, S E=0.275\right)$ may be considered relatively good, taking into account the number and the chemical diversity of the structures covered by this relationship.

When "1" value was assigned to variable $V$ for both oxygen- and fluorine-substituted compounds, no improvement was observed $\left(R^{2}=0.971, F=1065, S E=0.291\right)$. Taking into 
account the hydrogen bond acceptor character of the fluorine atoms, an improvement of the statistics for equation 4 should be expected, if the variable $V$ is related to hydrogen bonding. Such a result suggests that variable $V$ is related rather to the Brønsted acid-base behavior of the oxygen-containing compounds.

\subsection{Dependence of the $\log P$ parameter on index $I$ and water solubility}

As it is known, ${ }^{1,2} \log P$ involves the partition of a chemical compound between an organic solvent (usually 1-octanol) and water. Starting from this basic notion, we attempted to correlate $\log P$ values with the ratios $I / S_{w}$, where $S_{w}$ represents the water solubility (eq. 5a, obtained using those compounds for which both the experimental $\log P$ and $S_{w}$ were available, Table 1). Such a strategy may offer an easily accessible method for measuring $\log P$, being related to the real partition process (organic phase/water). A plot of $\log P$ calculated (eq. 5a) and the experimental $\log P$ is presented in Figure 5.

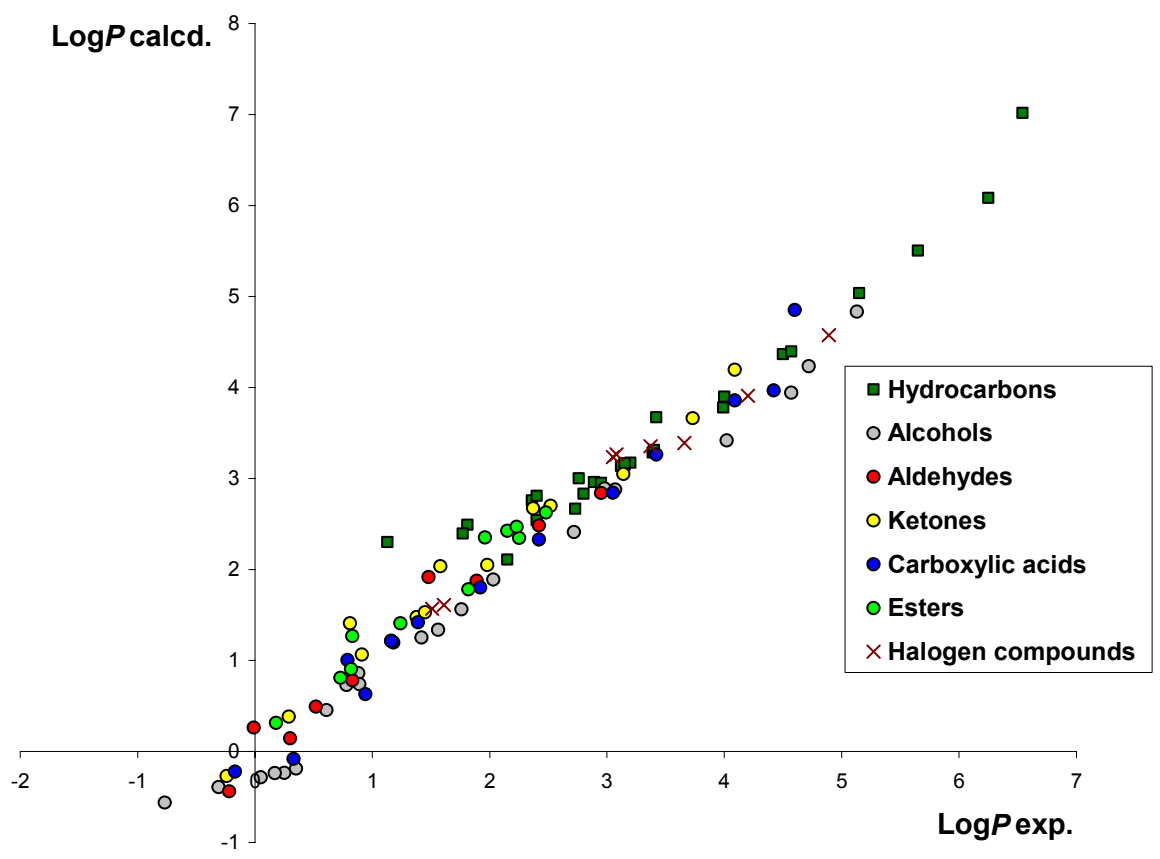

Figure 5. Plot of the $\log P$ calcd. (eq.5a) vs. $\log P$ exp. (Table 1).

$$
\begin{gathered}
\log P=0.809 \times \log \left(I^{*} / S_{w}\right)+0.066 \\
N=105 ; R^{2}=0.969 ; F=3183,72 ; S E=0.281 ; R_{C V}^{2}=0.965 ; Q=3.501
\end{gathered}
$$

where $S_{w}=$ experimental water solubility.

The resulted correlation equation (eq. 5a) was compared to Yalkowsky's equation applied to the same set of compounds (eq. 5b), ${ }^{4}$ showing an improvement of statistical parameters, when the 
Kovàts index is used together with water solubility. The improvement added by the retention index (which is related to the solubility in the organic phase) may depend on the stationary phase.

$$
\begin{gathered}
\log P=-0.823 \times \log S w+0.812 \\
N=105 ; R^{2}=0.950 ; F=1981,84 ; S E=0.353 ; R_{C V}^{2}=0.949 ; Q=2.762
\end{gathered}
$$

eq. $5 b$

\section{Estimation of water solubility on the basis of Kovàts retention indices}

The linear dependence between $\log P$ and $S_{w}$ discussed above is due to the physico-chemical definition of the $\log P$ parameter, i. e. the organic phase/water partition. Based on such a relationship, $\log S_{w}$ may be expressed as a linear function of the same parameters that describe $\log P$. Thus, the general model represented by eq. 3 (which gave the best results from all the tested models) was applied for estimation of $\log S_{w}$, resulting in eq. 6 :

$$
\log S_{w}=a \times I^{*}+b \times \mathrm{nBt}+c
$$

eq. 6

where: $I^{*}=I($ Kovàts index, Table 1$) / 100, \mathrm{nBt}=$ number of bonds.

Table 5. Coefficients $a, b, c$ and statistical parameters $\left(R, F, S E, R_{C V}^{2}, Q\right)$ in the case of eq. 6, for each class of compounds (according to Table 1)

\begin{tabular}{ccccccccccc}
\hline Eq. & Class & $\mathbf{N}$ & $\boldsymbol{a}$ & $\boldsymbol{b}$ & $\boldsymbol{c}$ & $\boldsymbol{R}^{2}$ & $\boldsymbol{F}$ & $\boldsymbol{S E}$ & $\boldsymbol{R}_{\boldsymbol{C V}}^{2}$ & $\boldsymbol{Q}$ \\
\hline 6a & Hydrocarbons & 30 & 0.217 & -0.236 & -0.93 & 0.931 & 184.4 & 0.372 & 0.905 & 2.593 \\
6b & Alcohols & 23 & -0.222 & -0.122 & 3.76 & 0.972 & 358.3 & 0.317 & 0.961 & 3.110 \\
6c & Aldehydes & 9 & -0.255 & -0.120 & 3.41 & 0.977 & 131.32 & 0.232 & 0.959 & 4.260 \\
6d & Ketones & 13 & -0.045 & -0.138 & 3.15 & 0.983 & 289.9 & 0.208 & 0.945 & 4.766 \\
6e & Carboxylic & 14 & -0.267 & -0.081 & 3.74 & 0.986 & 239.3 & 0.230 & 0.982 & 4.317 \\
& acids & & & & & & & & & \\
6f & Esters & 11 & -0.101 & -0.144 & 2.45 & 0.952 & 79.62 & 0.220 & 0.898 & 4.435 \\
6g & Halogen comp. & 8 & -0.408 & 0.068 & 2.05 & 0.987 & 201.47 & 0.156 & 0.954 & 6.368 \\
\hline
\end{tabular}

(') $R=$ Pearson's correlation coefficient; $F=$ Fisher test; $S E=$ standard error; $R_{C V}^{2}=$ cross validation coefficient; $Q=$ quality factor. 


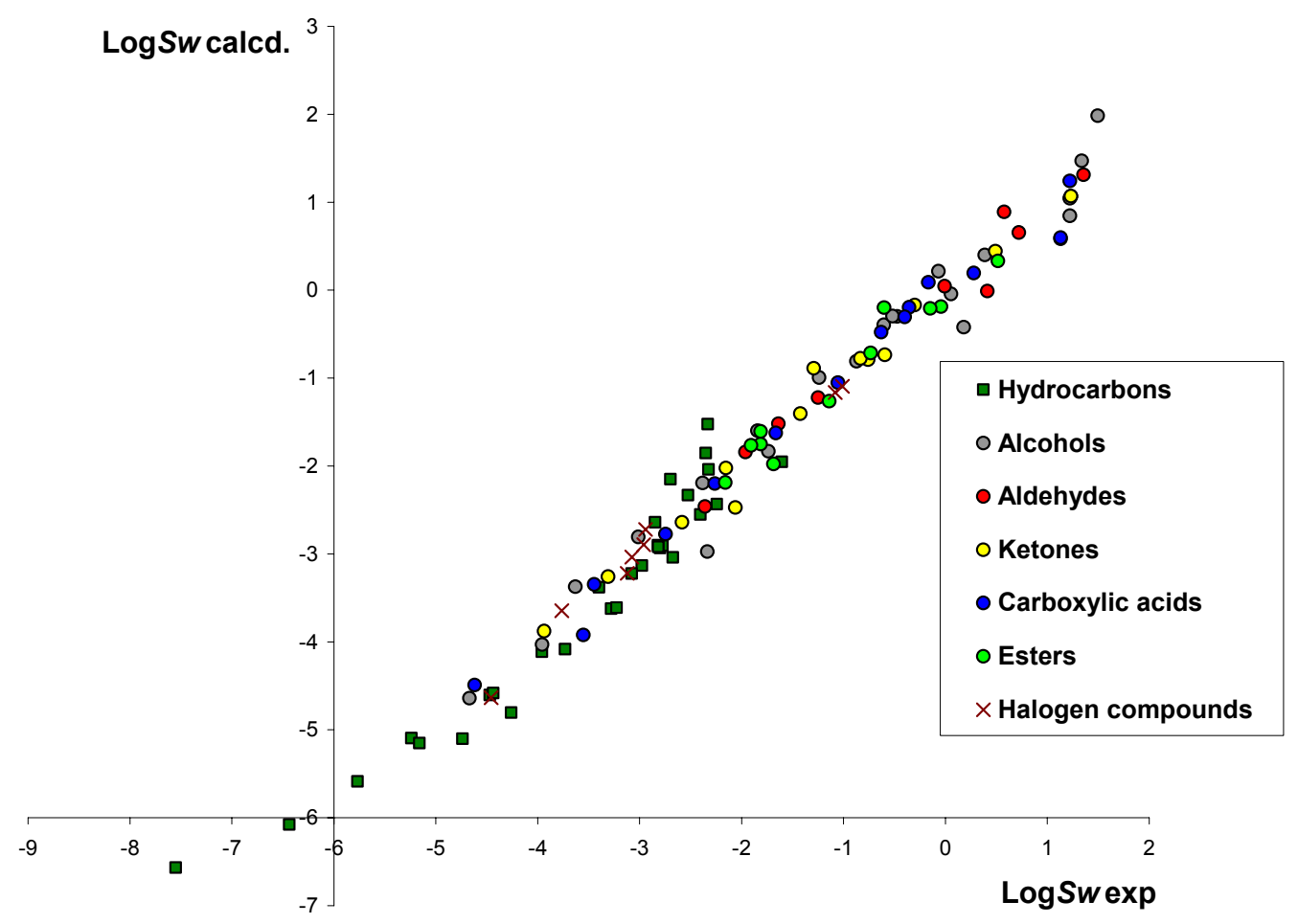

Figure 6. $\log S_{w}$ calcd. (eq. 6, Table 5), vs. $\log S_{w}$ exp.

The coefficients of eq. 6, corresponding to each class of compounds from table 1 , and the statistical parameters are presented in Table 5. This result, together with the plot of $\log S_{w}$ calcd vs. $\log S_{w} \exp$. (Figure 6), augment the validity of such a model for estimating the water solubility of various compounds.

Because both parameters $\log P$ and $\log S_{w}$ can be expressed by the same QSPR model involving index $I$, a new general relationship, suitable for the estimation of $\log P$ or $\log S_{w}$, is proposed as eq. 7:

$$
\log P \text { or } \log S_{w}=a \times I^{*}+b \times \mathrm{nBt}+c
$$

where the definitons of $I^{*}$, and $\mathrm{nBt}$ are those specified for eq. 3 and eq. 6 .

Values of the coefficients $a, b, c$ have been already presented for each calculated property and for each class of compounds from Table 1.

The present study based on the correlation between $\log P$ and Kovàts index underlines the possibility of using GLC for the estimation of the octanol/water partition coefficients instead of liquid chromatography, in the case of volatile compounds. The linear relationship between these two parameters within homologous series could be extended to more general relationships, applicable to sets of increased structural diversity (eqs. 2 - 5). In the present work, several descriptors related to the physico-chemical properties of the solutes were tested, but many other descriptors may give significant results. ${ }^{34,36}$ 
The intercorrelation of parameters is presented in Table 6 for the most general models, covering large datasets, namely for eq. 4 (Table 6a) and eq. 5a (Table 6b).

Table 6. Intercorrelation of parameters for eqs. 4 (6a) and $5 \mathbf{a}(\mathbf{6 b})$

(6a)

\begin{tabular}{lrrrrr}
\hline & \multicolumn{1}{c}{$\log P$} & \multicolumn{1}{c}{$I^{*}$} & \multicolumn{1}{c}{$\mathrm{nBt}$} & \multicolumn{1}{c}{$\mathrm{Sp}$} & \multicolumn{1}{c}{$V$} \\
\hline $\log P$ & 1 & & & & \\
$I^{*}$ & 0.458 & 1 & & & \\
$\mathrm{nBt}$ & 0.817 & 0.769 & 1 & & \\
$\mathrm{Sp}$ & -0.311 & 0.265 & -0.147 & 1 & \\
$V$ & -0.523 & 0.337 & 0.030 & 0.436 & 1 \\
\hline
\end{tabular}

$(6 \mathrm{~b})$

\begin{tabular}{lrrr}
\hline & \multicolumn{1}{c}{$\log P$} & \multicolumn{1}{l}{$\log S_{w}$} & $\log I^{*}$ \\
\hline $\log P$ & 1 & & \\
$\log S_{w}$ & -0.975 & 1 & \\
$\log I^{*}$ & 0.438 & -0.329 & 1 \\
\hline
\end{tabular}

Excepting the negative significant intercorrelation between $\log P$ and $\log S_{w}$, no other intercorrelation can be seen in Tables 6a and 6b. More pronounced intercorrelations of the descriptors may occur within particular sets from Table 1. Randić's orthogonalization procedure can be applied to the collinear parameters for each equation within each class of compounds. According to Randić, ${ }^{37,38}$ orthogonalization of descriptors does not affect the statistical parameters $(R, F, \mathrm{SE})$ which are the same for both orthogonal and nonorthogonal models. The main reasons for using orthogonal descriptors are the stability and significance of the equation's coefficients. Analysis of the parameters and of the coefficients of the presented equations, employing orthogonal models, on several stationary phases, and using larger data sets, will be the subject of a more detailed future study.

A comparison between the estimating abilities of the proposed models towards $C \log \mathrm{P}^{1,31}$ and several known QSPR models (eg. AlogP,${ }^{14} \mathrm{MlogP}{ }^{15}$ and ACDlabs ${ }^{33}$ ) can be made through the residuals between the experimental and the calculated $\log P$ and $\log S_{w}$ values, as presented in Table 7. 
Table 7. Residuals of the experimental $\log P$ and $\log S_{w}$ values towards the corresponding values calculated through eq. $2-6$, and through some already known QSPR models

\begin{tabular}{|c|c|c|c|c|c|c|c|c|c|c|}
\hline & \multirow[b]{2}{*}{ Compound } & \multicolumn{7}{|c|}{$\log P$} & \multicolumn{2}{|c|}{$\log S_{w}$} \\
\hline & & $\mathrm{C} \log \mathrm{P}$ & $\mathrm{A} \log \mathrm{P}^{\mathrm{a}}$ & $\mathrm{Mlog}^{\mathrm{a}}$ & $\mathrm{Eq} 2$ & Eq. 3 & Eq.4 & Eq.5 & ACD & Eq.6 \\
\hline 1 & ethane & 0.06 & 0.53 & 0.05 & 0.34 & 0.03 & 0.22 & -0.68 & 0.69 & -0.55 \\
\hline 2 & propane & 0.08 & 0.62 & 0.08 & 0.37 & 0.06 & 0.25 & -0.40 & 0.43 & -0.21 \\
\hline 3 & n-butane & 0.08 & 0.69 & 0.16 & 0.34 & 0.07 & 0.26 & -0.07 & 0.12 & 0.15 \\
\hline 4 & n-pentane & 0.05 & 0.74 & 0.25 & 0.25 & 0.04 & 0.23 & 0.11 & -0.09 & 0.34 \\
\hline 5 & n-hexane & 0.13 & 0.89 & 0.48 & 0.30 & 0.13 & 0.32 & 0.10 & 0.04 & 0.16 \\
\hline 6 & n-heptane & 0.11 & 0.94 & 0.63 & 0.25 & 0.11 & 0.30 & 0.13 & -0.04 & 0.14 \\
\hline 7 & n-octane & 0.23 & 1.13 & 0.95 & 0.36 & 0.24 & 0.42 & 0.11 & 1.07 & -0.14 \\
\hline 8 & n-nonane & 0.20 & 1.17 & 1.13 & 0.36 & 0.21 & 0.40 & 0.15 & -0.09 & -0.18 \\
\hline 9 & n-decane & 0.27 & 1.86 & 1.43 & 0.49 & 0.29 & 0.47 & 0.17 & -0.13 & -0.36 \\
\hline 10 & n-undecane & 0.03 & 1.15 & 1.43 & 0.31 & 0.06 & 0.24 & -0.48 & 0.17 & -0.98 \\
\hline 11 & n-dodecane & -0.24 & 0.95 & 1.40 & 0.14 & -0.21 & -0.02 & - & - & - \\
\hline 12 & $\mathrm{n}$-tridecane & -0.07 & 1.20 & 1.83 & 0.42 & -0.03 & 0.15 & - & - & - \\
\hline 13 & n-tetradecane & -0.10 & 1.24 & 2.07 & 0.52 & -0.05 & 0.13 & - & - & - \\
\hline 14 & 2-methylpropane & 0.08 & 0.77 & 0.03 & -0.10 & -0.11 & 0.11 & -0.24 & 0.38 & 0.15 \\
\hline 15 & 3-methylheptane & - & - & - & - & - & - & - & 0.16 & -0.01 \\
\hline 16 & 2,4-dimethylpentane & - & - & - & - & - & - & - & 0.09 & 0.54 \\
\hline 17 & ethene & -0.14 & 0.18 & 0.43 & -0.75 & -0.14 & -0.06 & -1.17 & 0.79 & -0.81 \\
\hline 18 & propene & -0.02 & 0.46 & 0.55 & -0.39 & -0.03 & 0.05 & -0.63 & 0.40 & -0.29 \\
\hline 19 & 1-butene & 0.07 & 0.59 & 0.73 & -0.27 & 0.06 & 0.15 & -0.14 & 0.05 & 0.15 \\
\hline 20 & 1-pentene & -0.05 & 0.54 & 0.72 & -0.43 & -0.06 & 0.03 & -0.03 & -0.18 & 0.36 \\
\hline 21 & 1-hexene & 0.02 & 0.68 & 0.94 & -0.33 & -0.02 & 0.09 & 0.09 & -0.15 & 0.38 \\
\hline 22 & 1-heptene & 0.08 & 0.82 & 1.18 & -0.30 & 0.05 & 0.16 & 0.21 & -0.23 & 0.35 \\
\hline 23 & 1-octene & 0.13 & 0.94 & 1.42 & -0.23 & 0.11 & 0.22 & 0.17 & -0.15 & 0.15 \\
\hline 24 & $E$-2-octene & 0.01 & 0.86 & 1.29 & -0.36 & 0.02 & 0.10 & - & - & - \\
\hline 25 & 2-ethylhexene & -0.02 & 0.69 & 1.16 & -0.66 & -0.15 & -0.04 & - & - & - \\
\hline 26 & 2-butyne & 0.01 & -0.41 & -0.21 & 0.64 & -0.29 & -0.37 & - & - & - \\
\hline 27 & 1-octyne & -0.03 & -0.64 & 0.42 & -0.16 & -0.36 & -0.38 & - & - & - \\
\hline 28 & 2-octyne & -0.01 & -0.13 & 0.42 & -0.28 & -0.26 & -0.36 & - & - & - \\
\hline 29 & benzene & 0.01 & 0.32 & -0.11 & 0.53 & 0.05 & -0.16 & 0.04 & -0.35 & 0.35 \\
\hline 30 & toluene & 0.09 & 0.41 & 0.12 & 0.13 & 0.12 & -0.10 & 0.06 & -0.17 & 0.19 \\
\hline 31 & ethylbenzene & -0.02 & 0.38 & 0.21 & -0.26 & 0.01 & -0.21 & 0.00 & -0.16 & 0.13 \\
\hline 32 & styrene & 0.09 & 0.57 & 0.10 & -0.52 & 0.31 & -0.02 & 0.00 & 0.09 & -0.19 \\
\hline 33 & ethynylbenzene & -0.01 & -0.56 & -0.45 & 0.27 & 0.19 & -0.20 & -0.41 & 0.26 & -0.50 \\
\hline 34 & $o$-xylene & 0.03 & 0.32 & 0.18 & -0.37 & -0.01 & -0.23 & -0.02 & -0.15 & 0.13 \\
\hline 35 & $m$-xylene & 0.06 & 0.40 & 0.26 & -0.29 & 0.08 & -0.15 & 0.03 & -0.10 & 0.08 \\
\hline 36 & $p$-xylene & 0.01 & 0.35 & 0.21 & -0.33 & 0.02 & -0.21 & -0.02 & -0.10 & 0.10 \\
\hline
\end{tabular}




\begin{tabular}{|c|c|c|c|c|c|c|c|c|c|c|}
\hline 37 & mesitylene & -0.22 & 0.13 & 0.16 & -0.85 & -0.22 & -0.46 & -0.25 & -0.06 & -0.02 \\
\hline 38 & $\alpha$-pinene & 0.13 & 1.96 & 1.46 & -0.27 & -0.26 & -0.20 & 0.12 & 0.50 & 0.36 \\
\hline 39 & cyclohexane & 0.09 & 0.70 & 0.32 & 1.16 & -0.06 & -0.01 & - & - & - \\
\hline 40 & methanol & -0.01 & -0.41 & 0.04 & 0.24 & 0.09 & -0.05 & -0.21 & -0.62 & -0.49 \\
\hline 41 & ethanol & -0.07 & -0.30 & -0.14 & 0.18 & 0.07 & -0.09 & 0.08 & -0.74 & -0.14 \\
\hline 42 & 1-propanol & -0.04 & -0.27 & -0.10 & 0.06 & 0.06 & -0.05 & 0.49 & -1.01 & 0.38 \\
\hline 43 & 1-butanol & 0.06 & -0.09 & 0.08 & 0.05 & 0.11 & 0.06 & 0.02 & -0.13 & -0.29 \\
\hline 44 & 1-pentanol & 0.21 & 0.13 & 0.35 & 0.15 & 0.23 & 0.22 & 0.22 & -0.04 & -0.21 \\
\hline 45 & 1-hexanol & 0.15 & 0.15 & 0.44 & 0.08 & 0.15 & 0.17 & 0.14 & 0.14 & -0.25 \\
\hline 46 & 1-heptanol & 0.31 & 0.38 & 0.78 & 0.23 & 0.29 & 0.33 & 0.31 & 0.26 & -0.25 \\
\hline 47 & 1-octanol & 0.13 & 0.27 & -0.12 & 0.07 & 0.09 & 0.16 & 0.19 & 0.29 & -0.19 \\
\hline 48 & 1-nonanol & 0.55 & 0.77 & 0.52 & 0.49 & 0.48 & 0.59 & 0.60 & 0.37 & -0.21 \\
\hline 49 & 1-decanol & 0.57 & 0.86 & 0.76 & 0.60 & 0.51 & 0.61 & 0.63 & 0.44 & -0.26 \\
\hline 50 & 1-undecanol & 0.19 & 0.56 & 0.62 & 0.15 & 0.06 & 0.25 & 0.49 & 0.19 & 0.07 \\
\hline 51 & 1-dodecanol & 0.07 & 0.51 & 0.75 & 0.05 & -0.09 & 0.14 & 0.30 & 0.28 & -0.03 \\
\hline 52 & 2-methyl-1-butanol & -0.06 & -0.05 & -0.13 & -0.13 & -0.09 & -0.16 & -0.06 & 0.00 & -0.17 \\
\hline 53 & 3-methyl-1-butanol & 0.20 & 0.20 & 0.21 & 0.14 & 0.17 & 0.07 & 0.17 & 0.05 & -0.22 \\
\hline 54 & allyl alcohol & 0.16 & -0.09 & -0.03 & -0.53 & 0.19 & 0.24 & 0.41 & -0.92 & 0.17 \\
\hline 55 & 2-hexen-1-ol & 0.00 & 0.03 & 0.16 & -0.38 & -0.06 & 0.11 & - & - & - \\
\hline 56 & 2-butanol & 0.01 & -0.28 & -0.19 & 0.03 & -0.01 & -0.22 & 0.16 & -0.42 & -0.01 \\
\hline 57 & 2-hexanol & 0.10 & -0.04 & 0.17 & 0.10 & 0.04 & -0.09 & 0.20 & -0.05 & -0.06 \\
\hline 58 & 2-propanol & -0.02 & -0.32 & -0.30 & 0.15 & 0.02 & -0.27 & 0.33 & -0.85 & 0.18 \\
\hline 59 & 3-hexanol & -0.01 & -0.22 & 0.06 & 0.02 & -0.06 & -0.17 & - & - & - \\
\hline 60 & 2-methyl-2-propanol & -0.12 & -0.22 & -0.45 & 0.10 & -0.11 & -0.50 & 0.54 & -1.01 & 0.54 \\
\hline 61 & 2-methyl-2-butanol & -0.11 & -0.21 & -0.32 & 0.04 & -0.15 & -0.47 & 0.15 & -0.37 & 0.10 \\
\hline 62 & 2-methyl-2-pentanol & -0.14 & -0.16 & -0.20 & 0.03 & -0.18 & -0.50 & - & - & - \\
\hline 63 & 3-methyl-3-pentanol & -0.12 & -0.21 & -0.18 & -0.07 & -0.22 & -0.44 & - & - & - \\
\hline 64 & 3-methyl-3-heptanol & - & - & - & - & - & - & - & -0.03 & 0.10 \\
\hline 65 & $\alpha$-terpineol & 0.35 & 0.57 & 0.62 & -0.78 & -0.70 & -0.37 & 0.09 & 0.54 & 0.64 \\
\hline 66 & dimethylcyclohexanol & 0.07 & 0.23 & 0.49 & -0.40 & -0.36 & -0.32 & - & - & - \\
\hline 67 & cyclopentanol & 0.07 & -0.26 & -0.04 & -0.68 & -0.55 & -0.34 & 0.05 & -0.19 & 0.60 \\
\hline 68 & acetaldehyde & -0.12 & -0.04 & 0.10 & 0.29 & -0.14 & 0.25 & 0.22 & -0.57 & 0.04 \\
\hline 69 & propionaldehyde & 0.29 & -0.18 & 0.10 & 0.12 & 0.26 & 0.25 & 0.16 & -0.55 & 0.07 \\
\hline 70 & butyraldehyde & 0.05 & -0.11 & 0.18 & 0.07 & 0.04 & 0.25 & 0.05 & -0.41 & -0.05 \\
\hline 71 & hexanal & -0.11 & 0.04 & 0.45 & 0.08 & -0.09 & 0.27 & 0.02 & -0.32 & -0.03 \\
\hline 72 & heptanal & 0.00 & 0.11 & 0.63 & 0.16 & 0.03 & 0.28 & -0.06 & -0.18 & -0.12 \\
\hline 73 & octanal & -0.05 & 0.14 & -0.14 & 0.22 & 0.00 & 0.23 & 0.11 & -0.28 & 0.10 \\
\hline 74 & 2-methyl-1-propanal & 0.06 & -0.18 & 0.12 & -0.10 & 0.02 & 0.22 & - & - & - \\
\hline 75 & propenal & 0.00 & -0.53 & -0.10 & -0.20 & -0.03 & 0.31 & -0.27 & -0.12 & -0.31 \\
\hline 76 & E-2-butenal & -0.02 & -0.40 & -0.03 & -0.38 & -0.08 & 0.35 & 0.03 & -0.70 & 0.42 \\
\hline
\end{tabular}




\begin{tabular}{|c|c|c|c|c|c|c|c|c|c|c|}
\hline 77 & $E$-2-hexenal & -0.02 & -0.25 & 0.25 & -0.35 & -0.05 & 0.36 & - & - & - \\
\hline 78 & benzaldehyde & 0.02 & -0.11 & -0.29 & 0.10 & 0.06 & 0.73 & -0.44 & -0.45 & -0.12 \\
\hline 79 & acetone & -0.03 & 0.00 & -0.44 & -0.11 & -0.04 & -0.28 & 0.03 & -0.97 & 0.16 \\
\hline 80 & 2-butanone & -0.03 & -0.13 & -0.37 & -0.20 & -0.04 & -0.26 & -0.09 & -0.69 & 0.05 \\
\hline 81 & 2-pentanone & 0.06 & 0.03 & -0.15 & -0.14 & 0.05 & -0.17 & -0.16 & -0.36 & -0.13 \\
\hline 82 & 2-hexanone & 0.00 & 0.04 & -0.06 & -0.19 & -0.01 & -0.22 & -0.10 & -0.36 & 0.03 \\
\hline 83 & 2-heptanone & 0.07 & 0.19 & 0.19 & -0.07 & 0.06 & -0.15 & -0.07 & -0.16 & -0.02 \\
\hline 84 & 2-octanone & -0.07 & 0.24 & 0.12 & -0.12 & -0.08 & -0.28 & -0.30 & 0.11 & -0.13 \\
\hline 85 & 2-nonanone & 0.17 & 0.44 & -0.22 & 0.22 & 0.15 & -0.03 & 0.09 & 0.09 & 0.06 \\
\hline 86 & 2-decanone & 0.23 & 0.57 & 0.07 & 0.40 & 0.21 & 0.04 & 0.07 & 0.35 & -0.05 \\
\hline 87 & 2-undecanone & 0.07 & 0.47 & 0.14 & 0.36 & 0.04 & -0.13 & -0.11 & 0.52 & -0.06 \\
\hline 88 & 2-dodecanone & 0.00 & 0.48 & 0.32 & 0.45 & -0.03 & -0.19 & - & - & - \\
\hline 89 & 3-hexanone & 0.07 & -0.10 & 0.01 & -0.09 & 0.05 & -0.07 & -0.08 & -0.29 & -0.06 \\
\hline 90 & cyclopentanone & 0.07 & -0.34 & -0.29 & 0.58 & -0.23 & -0.36 & - & - & - \\
\hline 91 & cyclohexanone & -0.05 & -0.36 & -0.24 & 0.12 & -0.33 & -0.55 & -0.60 & -0.08 & 0.14 \\
\hline 92 & cycloundecanone & 0.00 & 0.21 & 1.01 & -0.19 & -0.11 & -0.26 & - & - & - \\
\hline 93 & cyclododecanone & -0.12 & 0.19 & 1.17 & -0.24 & -0.20 & -0.35 & - & - & - \\
\hline 94 & acetophenone & 0.00 & 0.01 & -0.52 & -0.15 & 0.51 & 0.34 & 0.05 & -0.86 & -0.41 \\
\hline 95 & carvone & 0.32 & 0.16 & 0.37 & -0.63 & 0.00 & -0.13 & 0.41 & 0.17 & 0.41 \\
\hline 96 & acetic acid & 0.02 & 0.06 & 0.22 & 0.12 & -0.06 & 0.04 & -0.21 & 0.00 & -0.02 \\
\hline 97 & propionic acid & 0.00 & -0.11 & 0.20 & -0.08 & -0.12 & 0.07 & -0.03 & -0.52 & 0.53 \\
\hline 98 & butyric acid & -0.07 & -0.10 & 0.20 & -0.10 & -0.11 & 0.01 & 0.12 & 0.17 & -0.26 \\
\hline 99 & valeric acid & 0.00 & 0.04 & 0.39 & -0.04 & 0.00 & 0.10 & 0.09 & 0.06 & -0.15 \\
\hline 100 & hexanoic acid & 0.00 & 0.11 & 0.55 & -0.01 & 0.03 & 0.11 & 0.21 & -0.06 & 0.00 \\
\hline 101 & heptanoic acid & -0.03 & 0.16 & 0.69 & -0.02 & 0.02 & 0.09 & 0.16 & 0.03 & -0.04 \\
\hline 102 & octanoic acid & 0.07 & 0.33 & 0.08 & 0.12 & 0.15 & 0.21 & 0.23 & 0.15 & -0.06 \\
\hline 103 & nonanoic acid & -0.09 & 0.25 & 0.13 & 0.01 & 0.02 & 0.06 & 0.45 & 0.18 & 0.03 \\
\hline 104 & decanoic acid & 0.05 & 0.46 & 0.50 & 0.20 & 0.19 & 0.22 & -0.25 & 0.45 & -0.10 \\
\hline 105 & undecanoic acid & -0.15 & 0.33 & 0.54 & 0.06 & 0.02 & 0.03 & 0.31 & 0.18 & 0.37 \\
\hline 106 & dodecanoic acid & -0.50 & 0.06 & 0.44 & -0.22 & -0.30 & -0.28 & -0.02 & 0.87 & -0.13 \\
\hline 107 & 2-methylpropionic acid & 0.30 & 0.35 & 0.04 & 0.14 & 0.12 & 0.18 & -0.05 & -0.19 & 0.08 \\
\hline 108 & 2-methylbutyric acid & 0.00 & -0.18 & 0.18 & -0.23 & 0.06 & 0.46 & 0.05 & -0.12 & -0.16 \\
\hline 109 & 3-methylbutyric acid & -0.10 & 0.01 & 0.16 & -0.07 & -0.10 & -0.13 & 0.41 & -0.08 & -0.10 \\
\hline 110 & 4-methylpentanoic acid & 0.00 & 0.19 & 0.42 & 0.11 & 0.07 & -0.05 & - & - & - \\
\hline 111 & methyl acetate & 0.00 & 0.16 & 0.05 & -0.03 & -0.11 & -0.13 & -0.13 & -0.20 & 0.18 \\
\hline 112 & ethyl acetate & 0.02 & 0.36 & 0.14 & -0.05 & -0.03 & -0.08 & -0.08 & -0.20 & 0.14 \\
\hline 113 & 2-methylbutyl acetate & -0.01 & 0.48 & 0.56 & 0.05 & 0.07 & -0.09 & - & - & - \\
\hline 114 & propyl acetate & 0.00 & 0.35 & 0.24 & -0.06 & 0.00 & -0.10 & -0.17 & -0.06 & -0.02 \\
\hline 115 & butyl acetate & 0.05 & 0.47 & 0.45 & 0.02 & 0.09 & -0.03 & 0.04 & -0.16 & 0.12 \\
\hline 116 & 3-methylbutyl acetate & -0.05 & 0.65 & 0.52 & -0.04 & 0.07 & -0.14 & -0.10 & 0.11 & -0.06 \\
\hline
\end{tabular}




\begin{tabular}{llccccccc|cc}
117 & propyl butyrate & 1.44 & 0.13 & 0.42 & -0.04 & -0.04 & -0.14 & -0.28 & 0.11 & -0.14 \\
118 & methyl propionate & 0.03 & 0.13 & 0.23 & 0.01 & 0.04 & 0.02 & -0.08 & -0.09 & 0.06 \\
119 & propyl formate & -1.42 & -0.02 & 0.24 & 0.19 & 0.06 & 0.00 & -0.44 & 0.29 & -0.40 \\
120 & isobutyl isobutyrate & 0.00 & 0.14 & 0.42 & -0.18 & -0.10 & -0.33 & -0.15 & 0.07 & 0.03 \\
121 & isopentyl isovalerate & 0.00 & 0.64 & 0.94 & 0.23 & 0.07 & -0.23 & - & - & - \\
122 & benzyl acetate & 0.00 & 0.36 & -0.12 & -0.31 & -0.37 & -0.09 & -0.39 & -0.40 & 0.29 \\
123 & methyl benzoate & 0.12 & 0.55 & 0.20 & 0.19 & 0.25 & 0.84 & -0.24 & -0.20 & -0.21 \\
124 & 1-florooctane & 0.00 & 0.30 & 0.25 & -0.14 & -0.17 & -0.70 & 0.29 & -0.01 & -0.12 \\
125 & 1-bromoethane & 0.00 & 0.54 & 0.59 & -0.05 & -0.15 & -0.35 & 0.00 & -0.03 & 0.08 \\
126 & 1-bromopentane & 0.18 & -0.01 & 0.20 & 0.06 & 0.07 & -0.12 & 0.02 & 0.12 & -0.04 \\
127 & 2-bromooctane & 0.11 & 0.46 & -0.16 & 0.31 & 0.15 & -0.14 & 0.32 & 0.04 & 0.18 \\
128 & iodomethane & 0.05 & 0.27 & 0.01 & 0.15 & 0.06 & 0.00 & -0.06 & 0.01 & 0.08 \\
129 & 1-iodobutane & 0.03 & 0.59 & 0.59 & -0.02 & 0.11 & 0.07 & -0.19 & 0.16 & -0.06 \\
130 & 2-iodobutane & 0.00 & 0.82 & 1.13 & -0.11 & 0.15 & 0.08 & -0.19 & 0.34 & -0.22 \\
131 & 1-chlorohexane & 0.08 & -0.01 & 0.15 & -0.04 & 0.01 & -0.30 & 0.27 & -0.58 & 0.10 \\
132 & o-chlorotoluene & 0.07 & 0.23 & 0.48 & -0.17 & -0.22 & 0.33 & - & - & - \\
\hline & Average absolute deviation & $\mathbf{0 . 1 1}$ & $\mathbf{0 . 3 9}$ & $\mathbf{0 . 4 1}$ & $\mathbf{0 . 2 3}$ & $\mathbf{0 . 1 2}$ & $\mathbf{0 . 2 1}$ & $\mathbf{0 . 1 6}$ & $\mathbf{0 . 2 4}$ & $\mathbf{0 . 1 6}$ \\
\hline
\end{tabular}

${ }^{\mathrm{a}}$ Values for $\mathrm{A} \log \mathrm{P}$ and $\mathrm{M} \log \mathrm{P}$ were available by using the Dragon software. ${ }^{39}$

In order to compare the presented results with the data calculated by the mentioned softwares, an average absolute deviation for the considered set was calculated for each model.

According to Table 7, average absolute deviations are smaller for eqs. 2 - 5 than for AlogP and $\mathrm{MolgP}$, and in the case of eq.3 they are almost equal with those for ClogP. For the calculation of $\log S_{w}$, eq. 6 shows better results compared to the ACDlabs software.

\section{Conclusions}

Studying the possibility of estimation the octanol-water partition coefficients and water solubility starting from GLC data (Kovàts retention indices) in the case of 132 volatile compounds, belonging to seven different chemical classes, six equations were formulated involving the Kovàts index and additional parameters, namely molar refractivity and surface tension (eq. 2), number of bonds (eq.3 and 6), accessible polar surface (eq.4) and the $I / S_{w}$ ratio (eq. 5a). As a generalization of the performed study, a new model (eq. 7) was proposed in order to estimate either $\log P$ or $\log S_{w}$ in terms of the Kovàts index and number of bonds. The linear relationship between $\log P$ and the Kovàts index formulated through eqs. $2-6$, with $R^{2}$ values between 0.927 and 0.993 , proves that GLC may offer a facile alternative for the estimation of the octanol/water partition coefficient for volatile compounds. Gas-liquid chromatography (GLC) is a simple and widely used technique for which very small samples are needed, compared to other physicochemical methods. Moreover, eq. 7 evidences the possibility of extending each of the presented 
models in order to calculate other properties, which are linearly dependent on $\log P$, such as bioconcentration factors ${ }^{11,13}$ or soil adsorption coefficients. ${ }^{12}$

This new approach based on gas chromatography alleviates the recent concerns in estimating $\log P$ when using liquid chromatography. ${ }^{17-21}$ Likewise in the case of HPLC and TLC, improvements in the accuracy of property determination by using GLC retention indices may be expected by refinements in selecting the appropriate stationary phase. Such aspects, together with refining the already obtained models, need further investigations.

\section{Supplementary Information}

This is available in a Table of the molecular descriptors used in the above correlations for all the volatile organic compounds that are discussed in the present communication.

\section{References}

1 Hansch, C.; Leo, A.: Substituent Constants for Correlation Analysis in Chemistry and Biology. Wiley: New York, 1979.

2 Leo, A.; Hansch, C.; Elkis, D. Chem. Rev. 1971, 71, 525.

3 Chiou, C. T.; Schmedding, D. W.; Block, J. H. J. Pharm. Sci. 1981, 70,1176.

4 Yalkowsky, S. H.; Valvani, S. C. J. Pharm. Sci. 1980, 69, 912.

5 Chiou, C. T. Environ. Sci. Technol. 1982, 16, 4.

6 Yalkowsky, S. H.; Valvani S.C.; Roseman, T. J. J. Pharm. Sci. 1983, 72, 866.

7 Delaney, J. S. J. Chem. Inf. Comput. Sc.i 2004, 44, 1000.

8 Banerjee, S. Environ. Sci. Technol. 1985, 19, 369.

9 Maikut, O. M.; Makitra, R. C.; Palchikova, E. T. Russ. J. Gen. Chem. 2007, 77, 2198.

10 Tewari, Y. B.; Miller, M. M.; Wasik, S. P.; Martire, D. E. J. Chem. Eng. Data 1982, 27, 451.

11 Papa, E.; Dearden, J. C.; Gramatica, P. Chemosphere 2007, 67, 351.

12 Briggs, G. G. J. Agric. Food. Chem. 1981, 29, 1050.

13 Gestel, V.; Oterman, K.; Canton, J. H. Regulatory Toxicology and Pharmacology 1985, 5,422 .

14 Ghose, A. K.; Crippen, G. M. J. Comp. Chem. 1986, 7, 565.

15 Moriguchi, I.; Hirono, S.; Liu, Q.; Nakagome, I.; Matsuchita, Y. Chem. Pharm. Bull. 1992, 40, 127.

16 Jäntschi, A., Bolboaca, S. D. Int. J. Quant. Chem. 2007, 107, 1736.

17 Kaliszan, R.; Haber, P.; Baczec, T.; Danuta, S. Pure App.l Chem. 2001, 73, 1465.

18 Gianinis, C.; Tsantili-Kakoulidou, A. J. Liq. Chromatogr. Rel. Technol. 2008, 31, 79.

19 Kossoy, A. D.; Risley, D. S.; Kleyle, R. M.; Nurok, D. Anal. Chem. 1992, 64, 1345. 
20 Cserhati, T.; Forgacs, E. J. Chromatogr. A 1994, 660, 313.

21 Beteringhe, A.; Radutiu, A. C.; Bem, M.; Constantinescu, T.; Balaban, A. T. Internet. Electron. J. Mo.l Des. 2006, 5, 237.

22 Kovàts, E. Helv. Chim. Acta 1958, 411915.

23 Abraham, M. H. Chem. Soc. Rev. 1993, 73.

24 Patte, F.; Etcheto, M.; Laffort, P. Anal. Chem .1982, 54, 2239.

25 Laffort, P.; Chauvin, F.; Dallos, A.; Callegari, P. J. Chromatogr. A 2005, 1100, 90.

26 Wang, I. H.; Wong, P. K. Chemosphere 2003, 50, 499.

27 Cruciani G.; Baroni, M.; Clementi, S.; Constantino, G.; Riganelli, D.; Skagerberg, B. J. Chemometrics 1992, 6, 335.

28 Katritzky, A. R.; Lobanov, V. S.; Karelson, M. CODESSA: A Reference Manual (Version 2.0), Gainesville, Florida, 1994.

29 Beteringhe, A.; Balaban, A. T.; ARKIVOC 2004, (i), 163.

30 Beteringhe, A.; Filip, P.; Tarko, L. ARKIVOC 2005, $(x), 45$.

31 Bio Loom program \& database[http://www.biobyte.com/bb/prod/bioloom.html].

32 Syrracuse Research Corporation: free demos \& databases. [http://www. syrres.com/esc/free_demos.htm].

33 [http://www.acdlabs.com/download/chemsk.html].

34 Todeschini, R.; Consonni, V. Handbook of Molecular Descriptors. Wiley-VCH: New York, 2000 .

35 HyperChem $^{\mathrm{TM}}$ release 6.01 for Windows.

36 Devillers, J.; Balaban, A. T. Eds. Topological Indices and Related Descriptors in QSAR and QSPR. Gordon and Breach; The Netherlands, 1999.

37 Randić, M. J. Chem. Inf. Comput. Sci. 1991, 31, 311.

38 Randić, M. New J. Chem. 2000, 24, 165.

39 Dragon 5.5 evaluation version.[http://www.talete.mi.it/download/download.php]. 